\title{
PREDICTING ELECTRONIC CIGARETTE USE AMONG ADULTS IN THE PHILIPPINES
}

\author{
Fahad Khamis D. Aljaberi', Johnny J. Yao Jr. ${ }^{2}$ \\ 1. Vicente Sotto Memorial Medical Center, Philippines \\ 2. Cebu Normal University, Cebu City, Philippines
}

Correspondence: johnnyyaojr@gmail.com

\section{ABSTRACT}

\section{BACKGROUND:}

The Philippines has one of the highest cigarette smoking rates in Southeast Asia. Tobacco prevention and control efforts should not be a one-size-fits-all approach. One of the most recent and highly marketed way of cutting down smoking is the use of E-cigarettes. But its use may also have potential harmful effects which would be similar to cigarette smoking.

PURPOSE:

This study aimed to determine the factors predicting electronic cigarette use among adults in a large metropolitan area in the Philippines.

\section{METHODS:}

The study used a descriptive-correlational multivariate research design. Adults who are at least 18 years of age, who are electronic cigarettes users, dual users (electronic cigarette and cigarette users), and non-smokers were chosen for this study. The researchers utilized a researcher- made questionnaire based on the Theory of Planned Behavior (TPB) in gathering the data.

\section{RESULTS:}

Multiple regression analysis suggests that positive attitude and high perceived behavioral control significantly predict intent to use electronic cigarettes. Moreover, intent to use is a significant predictor of actual e-cigarette use.

\section{CONCLUSION:}

People who have positive attitudes and high perceived behavioral control towards e-cigarette use are most likely to have higher intent to use e-cigarettes. Further, people who have high intent to use e-cigarettes will most likely use e-cigarettes. With reverence to the findings of this study, health managers and professionals should look into how e-cigarettes are being marketed to the public which may shape their attitude and behavior. Lastly, further studies should be conducted on other variables that may predict electronic cigarette use and measure health outcomes.

\section{KEYWORDS}

electronic cigarettes, predictors, adults, vaping, health behavior, health promotion, Filipino adults 


\section{BACKGROUND}

The Philippines has one of the highest cigarette smoking rates among countries in Southeast Asia [1]. According to a survey in 2015, there are 13.1 million Filipino adults ranging from 15- 34 years old who engage in tobacco smoking. Tobacco cigarette users smoke an average of eleven cigarette sticks per day. The average age when people start smoking is 18 years of age for both men and women. [2] Additionally, tobacco cigarette is the only product taken that could destroy and deteriorate the human body when used directly. The United States top cause of preventable death is tobacco cigarettes, killing 480,000 people annually having increase deaths than HIV, substance abuse, and traumatic casualties combined. smoking increases the risk of neurovascular, cardiovascular, neurovascular, oncologic and endocrine disease. The average life span decreases at least 10 years in tobacco cigarette smoking. [3] There are many smoking cessation programs being implemented to be able to address this health problem. But tobacco prevention and control efforts should not be a one-size-fits-all approach due to various factors that determine its effectiveness. One of the most recent and highly marketed way of cutting down cigarette smoking is the use of E-cigarettes or commonly known as vaping. This has increased in popularity especially among adults. But its use may also have potential harmful effects which would be similar to cigarette smoking. The U.S. Food and Drug Administration (FDA) even initiated implementing control of marketing sales and electronic cigarette production rules in 2016 [4].

Studies found out that electronic cigarettes use leads to potential risks in health due to the presence of a number of potentially toxic substances that can directly affect people's health. Evidence on the use of electronic cigarettes among the youth suggests that they have a higher risk of cardiovascular, neurological and respiratory disease. [5-7] There is an increasing number of Asian governments that are currently taking reasonable efforts to protect the health of users by regulating the sale, marketing and electronic cigarettes use, to decrease exposure on youth to products consisting tobacco and nicotine, and tobacco-free laws reinforcement strategies. [8] Further research must be done about this topic to provide quality evidence as basis for policies and programs related to ecigarette use. There is limited evidence on several areas related e-cigarette use. Some areas that could be explored would be the effects of converting from smoking tobacco cigarette to vaping and its potential to reduce future negative health outcomes; behavioral studies customizing electronic cigarette products and its role in cessation effort; toxicity and exposure studies; and flavor preferences and its role in smoking cessation among adults [8-9]. Among all the research areas that can be explored, studying the factors affecting health behavior of people is one of the most common but significant research that can be undertaken to understand e-cigarette use. [10] There may be several possible factors why people use electronic cigarette. It may be because they want to look for smoking cessation alternative, taste a new flavor, relieve their stress, quit tobacco smoking, join a new smoking trend, and feel that it is readily available and accessible. Unfortunately, most studies only focus on factors influencing tobacco or cigarette smoking. It is crucial for health professionals to understand the factors of a behavior that might have long lasting implications to a person's health. This would be beneficial as basis for planning health policies and recommendations.

\section{OBJECTIVE}

The study aimed to determine the factors predicting electronic cigarette use among adults in a large metropolitan area in the Philippines.

\section{METHODS}

The study used a descriptive-correlational multivariate research design. This design included three variables (attitude, subjective norm, and perceived behavioral control) together to determine if they predict behavioral intention of electronic cigarette use. Furthermore, the study determined if behavioral intention is a predictor of actual e-cigarette use.

The research was conducted in Metro Cebu, which is the main urban capital of Cebu province in the island of the Philippines. The researchers utilized consecutive sampling for 1 week. The researchers' criteria were adults aged 18 years of age and above, at least high school graduate, who are current electronic cigarettes users for at least 1 year, dual users (electronic cigarette and cigarette users), current smokers and non-smokers. The researchers recruited the participants in the community and local vape or e-cigarette shops. The estimated sample size was determined using $G$ Power Software Version 3. Computed sample size is 120 respondents (medium effect size [0.15]; 
[a=0.05]; power [0.95], number of predictors is 3). There was a total of 124 respondents that were included in the study.

A researcher-made questionnaire based on using Theory of Planned Behavior was used to gather the data. This questionnaire includes the respondent's years of smoking electronic cigarettes and measures attitudes, subjective norm, perceived behavioral control, behavioral intention using a four-point Likert scale measuring agreement (4Strongly Agree, 3- Agree, 2- Disagree, 1-Strongly Disagree). Attitudes measure the degree to which a person has a favorable or unfavorable evaluation of using e-cigarettes. Subjective norms measure the belief about whether most people approve or disapprove of e-cigarette use. It relates to a person's beliefs about whether peers and people of importance to the person think he or she should use ecigarettes. Perceived behavioral control measures a person's perception of the ease or difficulty of using ecigarettes. Behavioral intention measures the motivation of the person to use e-cigarettes. The actual e-cigarette use was determined by asking the respondents the average amount of e-juice, e-liquid or vape juice used per week as measured in milliliter ( $\mathrm{ml}$ ).

The research tool was validated by three experts in the fields of public health, nursing, research methodology, and health professions education. The tool was also translated to local dialect using a back-translation process by two individuals who are bilingual. Pilot testing of the researchermade questionnaire was conducted on 20 respondents. The overall reliability of the tool is Cronbach's alpha (a) = 0.91. The Cronbach's alpha (a) for the attitude subscale is
0.84, subjective norm subscale is 0.79 , and perceived behavioral control subscale is 0.70 .

In order to provide the necessary protection for the respondents, the research proposal was submitted to the Ethics Review Committee (ERC) of the Cebu Normal University. The data gathering was done with utmost care, confidentiality, and anonymity. The rationale of the study was presented to the respondents as well as the explanation of the informed consent. One of the researchers was present for any clarifications and answer queries about the instrument. The questionnaires took about 10 to 15 minutes to finish and were collected on the same day.

The data collected was analyzed using IBM SPSS statistical software version 23. Descriptive statistics including means and standard deviations were calculated for the continuous variables and percentages and frequencies for categorical variables. Multiple regression was utilized to determine the predictors of behavioral intention and electronic cigarette use

\section{RESULTS}

Table 1 shows the respondents are mostly male (82\%), single $(81 \%)$, and electronic cigarette user (48\%). Furthermore, the average age of the respondents is 27 years old (SD $=5.83$ ). The youngest respondent is 18 years of age. The oldest respondent is 49 years of age. The mean electronic cigarette use is 3 years ( $S D=3.17)$. The mean amount of use (ml) of vape liquid/juice is 58 milliliters (SD $=55.54$ ).

TABLE 1. PROFILE OF THE RESPONDENTS

\begin{tabular}{lll} 
PROFILE & FREQUENCY & PERCENTAGE \\
\hline Sex & 102 & \\
Male & 22 & $82 \%$ \\
Female & & $18 \%$ \\
Civil Status & 101 & \\
$\quad$ Single & 22 & $81 \%$ \\
$\quad$ Married & 1 & $18 \%$ \\
$\quad$ Widow & & $1 \%$ \\
Current Users & 60 & \\
$\quad$ Electronic Cigarette User & 20 & $48 \%$ \\
$\quad$ Cigarette Smoker & 18 & $16 \%$ \\
$\quad$ Dual Smoker & 26 & $15 \%$ \\
$\quad$ Non-Smoker & & $21 \%$ \\
\hline
\end{tabular}




\begin{tabular}{lll}
\hline & Mean & SD \\
\hline Age & 27.23 & 5.83 \\
Years of Electronic & 3.24 & 3.17 \\
$\begin{array}{l}\text { Cigarette Use } \\
\text { Years of Cigarette Use }\end{array}$ & 7.96 & 6.62 \\
Amount of use $(\mathrm{ml})$ & 57.93 & 55.54 \\
\hline
\end{tabular}

Table 2 shows the prediction model 1 is statistically significant, $\mathrm{F}(150.16, \mathrm{p}<.001)$ and presents that the regression model has an $\mathrm{R}^{2}$ of .71 . This means that about $71 \%$ variability of behavioral intention, is predicted by attitude and perceived behavioral control. There may be extraneous variables not included in the model that can account for the remaining $29 \%$ of the variability

\section{TABLE2. REGRESSION ANALYSIS OF VARIABLES}

\begin{tabular}{|c|c|c|c|c|c|c|}
\hline MODEL & $R^{2}$ & $\boldsymbol{F}$ & B & SE (B) & $95 \% \mathrm{Cl}$ & B \\
\hline Model 1: DV = Behavioral Intention & $.71^{* * *}$ & 150.16 & & & & \\
\hline Path a: IV = Attitude & & & $.92^{* * *}$ & .09 & {$[0.74,1.11]$} & $.65^{* * *}$ \\
\hline Path b: IV = Subjective Norms & & & .13 & .14 & {$[-0.14,0.39]$} & .08 \\
\hline Path c: IV = Perceived Behavioral Control & & & $.54^{* * *}$ & .14 & {$[0.26,0.82]$} & $.25^{* * *}$ \\
\hline Model 2: DV = Actual Use & $.22^{* * *}$ & 45.79 & & & & \\
\hline Path d: IV = Behavioral Intention & & & $19.82^{* * *}$ & 3.38 & $\begin{array}{l}{[13.12} \\
26.51]\end{array}$ & $.47^{* * *}$ \\
\hline
\end{tabular}

Note. $\mathrm{n}=124 . \mathrm{B}=$ unstandardized beta. $\mathrm{SE}=$ standard error. $\mathrm{Cl}=$ confidence interval. $\beta=$ standardized beta. $\mathrm{DV}=$ dependent variable. IV = independent variable.

${ }^{* * *} \mathrm{p}<.001$.

Table 2 also shows the unstandardized and standardized regression coefficients of the predictors using the regression analysis to predict electronic cigarette use. It indicates that the independent variables-attitude $(\beta=.65, p<.001)$ and perceived behavioral control $(\beta=.253, p<.001)$ are significant predictors to the dependent variable, behavioral intention. Both attitude and perceived behavioral control have positive coefficients, which means that an increase or decrease of its value will subsequently increase or decrease the level of behavioral intention, respectively. The results suggest that adults having increase value of attitude and perceived behavioral control are more likely to have a higher intention to engage in electronic cigarette use. Moreover, subjective norms is not a significant predictor $(\beta=.08, p>.05)$, which may due to multicollinearity effect. Table 2 also shows the prediction model 2 , which is statistically significant, $F(45.79, p<.001)$ and shows that the regression model has an $R^{2}$ of .22. This means that about $22 \%$ of the variability of behavioral intention is predicted by actual cigarette use. The remaining $78 \%$ of the variability is unaccounted for and may be due to other variables that were not included in the study.

\section{DISCUSSION}

Most of the respondents who are e-cigarette smokers are male and single. According to Perikleous and colleagues, [11] the increased vaping prevalence among males can be influenced by marketing strategies or sociocultural characteristics and recent trends. In most cases, males are most probably adopting the technology early, and have effortless accessibility of the product. Furthermore, the study demonstrated that higher risk of electronic cigarette use in men may exist, partly, because men view lower in harm perception on electronic cigarette meanwhile females tend to appraise lower risk and avoid risky behaviors only when they recognize severe risk. [11] 
In a study of Perialathan and colleagues [12] in Malaysia, there is a higher prevalence of singles that used electronic cigarettes. In a study by Alanazi and colleagues, [13] single status respondents were significantly greater than other status groups to have positive attitude, subjective norm, perceived behavioral control, and behavioral intentions toward cigarettes.

In the regression analysis of the study, attitude and perceived behavioral control are significant predictors of behavioral intention. Moreover, subjective norm is not a significant predictor of behavioral intention. This is similar to the study of Alanazi and colleagues that showed behavioral intention's strongest predictors were attitude and perceived behavioral control, meanwhile subjective norm had not directly influence in the intention to use cigarettes. [13] It is found to be consistently utilized in some TPB researches that subjective norm were the weakest predictor and non-significant predictor in predicting an intention. [13] Although, the study showed subjective norm was not the intention's strong predictor, subjective norm however had indirect effects on intention through attitude and perceived behavioral control. [13]

These possible factors could be affected by the information that people get due to the limited scientific evidence and marketing strategies related to e-cigarettes. Since electronic cigarettes is a relatively new product in the market, there is insufficient data on its safety and would warrant extensive research on scientific information about its potential harmful effects and toxicity. [14] This will affect not only electronic cigarette users but also those who inhale secondhand "vaping". [14] Electronic cigarette use as a lifestyle on social media can lead viewers to develop positive social norms about electronic cigarette use, thereby increasing their susceptibility to electronic cigarette use. In particular, social media users may come to view electronic cigarette use as a socially acceptable behavior after observing electronic cigarette companies' discourse on social media. Individuals may become open to electronic cigarette use when electronic cigarette companies' social media posts are shared by their in-group members, such as friends or acquaintances on social media. [15] On the other hand, the actual behavioral control's importance affected by a person's available resources and opportunities. In the theory of planned behavior, perceived behavioral control plays an important part and considering it in the prediction of intentions and actions. [10] However, intentions are influenced by other factors and due to these added factors, two persons with different insights of behavioral control can have equally strong intentions. This is apparent in the regression model that there are still variables that cannot account for the variability of the outcomes such as intent and actual use. Furthermore, behavioral intention is expected to influence the motivational factors influencing a behavior and indicates how much of an effort a person is planning in order to perform the behavior. E-cigarettes are readily available due to the increase in stores and shops that sell these products. There are no strict regulations in the marketing and selling of e-cigarettes which could contribute to the ease in access as well as availability of these products to the general public. As a general rule, the stronger the behavioral intention the more likely the behavior will be performed. [10]

Another study by Bierman, [16] showed that the only significant variable was perceived behavioral control and proposed that quitting intention would be better by increasing a person's sense of control over believing to quit. The study findings supported other studies related tobacco cessation in which the most significant predictor of intention was perceived behavioral control.

In a study done in Zahedan University of Medical Sciences, predictors toward smoking were willingness to smoke, and unfavorable attitude. [17] The willingness to smoke was a positive predictor of smoking experience and unfavorable attitude toward smoking cigarette and intention to not smoke were negative predictors. The smoking willingness compared to other variables was a stronger predictor for smoking experience. [17]

\section{CONCLUSION}

Attitude and perceived behavioral control influence behavioral intention and subsequently behavioral intention influence actual use. People who have a positive attitude and high perceived behavioral control towards ecigarettes use are most likely to have a higher intention to use electronic cigarettes. People who have high behavioral intention to use electronic cigarette will most likely use electronic cigarette. Understanding the factors that would determine e-cigarette use would be important for policy makers and program planners to address concerns related to potential harmful effects of its use. It is important that the public is presented with quality information and evidence so that people may be able to make more informed decisions since this could potentially 
shape their attitude towards e-cigarette use. Limiting the access and availability of the public to e-cigarettes may reduce its use and subsequently any future negative outcomes to public health. Future studies should investigate other variables that may predict electronic cigarette use and measure health outcomes of electronic cigarette use.

\section{References}

1. Garcia, G. (2010) Factors associated with Cigarette Smoking among Filipinos in the Philippines. Retrieved October 14, 2019 from

https://www.researchgate.net/publication/266900954

2. Department of Health (2015). Global Adult Tobacco Survey: Country Report 2015. Retrieved May 12, 2019 from

https://www.who.int/tobacco/surveillance/survey/gat s/phl_country_report.pdf?ua=1

3. Ross, J (2019), E- Cigarettes: Good News, Bad news Retrieved September 11, 2019 from https://www.health.harvard.edu/blog/electroniccigarettes-good-news-bad-news-2016072510010

4. Medical News Today. (2018). Are e-cigarettes a safe alternative to smoking? Retrieved April 1, 2019 from https://www.medicalnewstoday.com/articles/216550. php

5. IPSOS (2016) Philippines Adult Smoker Survey Retrieved October 13, 2019 from https://www.factasia.org/wpcontent/uploads/pdf_files/survey-resultsphilippines.pdf

6. American Lung Association (2019) Retrieved

September 11, 2019 https://www.lung.org/stopsmoking/smoking-facts/impact-of-e-cigarettes-onlung.html

7. National Institute on Drug Abuse Advancing Addiction Science. (2018) Electronic Cigarettes. Retrieved September 11, 2019 from

https://www.drugabuse.gov/publications/drugfacts/el ectronic-cigarettes-e-cigarettes

8. Asian Vape Association. (2019) E-Cigarettes in Asia. Retrieved April 1, 2019 from http://www.asianvapeassociation.org/what-we-do/ecigrettes-in-asia/

9. Department of Health (2019) Electronic Cigarette. Retrieved April 1, 2019 from https://www.doh.gov.ph/node/64
10. Ajzen, I. (1991) The Theory of Planned Behavior Retrieved on January 2, 2020 from

http://citeseerx.ist.psu.edu/viewdoc/download?doi=1 $\underline{0.1} 1.317 .9673 \&$ rep $=$ rep $1 \&$ type $=p d f$

11. Perikleous, E., Steiropoulos P., Paraskakis E., Constantinidis, T., \& Nena, E.(2018). E-Cigarette Use Among Adolescents: An Overview of the Literature and Future Perspectives Retrieved November 30, 2019 from

https://www.frontiersin.org/articles/10.3389/fpubh.201 $\underline{8.00086 / f u l l}$

12. Perialathan, K., Rahman, A., Lim, K., Adon, Y., Ahmad, A., Juatan, N., \& Jaafar, N. Prevalence and associated factors of ever use of Electronic Cigarettes: Findings from a hospitals and health clinics study based in Malaysia Retrieved November 30, 2019 from http://www.tobaccoinduceddiseases.org/Prevalence -and-associated-factors-of-ever-use-of-electronicncigarettes-Findings, 99258,0,2.html

13. Alanazi N., Lee,J., Dos Santos, H., Job, J., \& Khaled Bahji (2017) The use of planned behavior theory in predicting cigarette smoking among Waterpipe smokers Retrieved on December 5, 2019 from https://tobaccoinduceddiseases.biomedcentral.com/ articles/10.1186/s12971-017-0133-z

14. Majeed, B. (2015) Electronic Cigarettes: Associated Beliefs and Reasons for Use among US Adults Retrieved September 11, 2019 file://C:/Users/user\%202/Downloads/ 1 le888cef0873d 6503ea10b7a3208f2d3e5f.pdf

15. Kim, J.K., Pardun, C.J., \& Overton, H. (2019) Electronic Cigarette Companies' Twitter Messages: Public Interest (Mis) communication Retrieved on December 5, 2019 from file:///C:/Users/Client/Downloads/106450Article\%20Text-159089-1-10-20190424.pdf

16. Bierman V. (2012) Explaining Intention to Stop Smoking with the Theory of Planned Behavior and Selfexempting Beliefs Retrieved on December 5, 2019 from

https://libres.uncg.edu/ir/uncg/f/Bierman uncg 0154 D 10883.pdf

17. Farshidi H., Aghamolaei, T., Hosseini, Z., Nejad A.G., \& Hosseini, F.A(2017) Cigarette Smoking Based on Prototype Willingness Model in Male High School Students Retrieved on December 5, 2019 from http://ihrba.com/en/articles/63209.html 